\title{
The Research On Applicability Of Amended KMV Model With Different Industries
}

\author{
Yang Yang \\ School of Management and Economics, University of Electronic Science and Technology of China, Chengdu 610054, \\ China \\ Li Li ${ }^{1,2}$, Zongfang Zhou' ${ }^{1}$, Wenying Fei $^{3}$ \\ 1School of Management and Economics, University of Electronic Science and Technology of China, Chengdu 610054, \\ China \\ 2School of Mathematics, Yunnan Normal University, Kunming 650092, China \\ 3Research Center of Corporate Governance, NaiKai University, Tianjin 300071, China
}

\begin{abstract}
The determination of the default point is the key to applying the KMV model. In the traditional research, the default point is equal to the sum of short term debt and half of the long term debt empirically based on the credit data of American companies. But whether it is fit for the Chinese companies and whether it is sensitive to industries depend on further research. This paper amends the parameters of default point. Further the paper also analyzes the applicability of amended KMV model in different industries based on the data of Chinese listed companies.
\end{abstract}

Keywords: KMV model; Default point; Different industries; Credit data

\section{Introduction}

The KMV model is a credit risk measurement established by KMV company in 1997. There are four main advantages which led this model widely used in the areas of credit risk assessment and the forecasting of financial distress. First, the KMV model is superior to the timeliness of the assessment models. The KMV model uses the real-time data. It can update the probability of default in real time based on the data of securities market; second, the assumption of KMV model is week. The efficient market assumption is not required. This is very applicable for the week effective securities market of China; third, the KMV model is a forward-looking method. The data used in the model reflects the expected value of the company and the judgment of the company's future development trends of the investors; fourth, the KMV model is a base method which is different from the ordinal method. It can not only reflect the credit risk level of the order but also reflect the credit risk level of the degree of difference.

A large number of empirical researches have shown that the KMV model integrates the advantage of both financial reports and market price. It reflects the company's history situation on one hand, and reflects the trends of the company's future development on the other hand. ${ }^{1}$ Jeff Bohn (2003) had compared the credit risk evaluation results of KMV model and the standard \& poor's. The research concluded that the KMV is suitable for assessing the credit risk with low quality of information. ${ }^{2}$ Kealhofer and Kurbat (2001) had also compared the credit risk evaluation results of $\mathrm{KMV}$ model and the ROA method of Moody's corporation. Their results illustrated that the forecast accuracy of KMV model is higher than the forecast accuracy of the ROA method. ${ }^{3}$ Besides, Matthew Kurbat and Irina Korablev (2002) ${ }^{4}$, Peter Crodbie and Jeff Bohn (2003) ${ }^{5}$, Stefan M. Denzler (2006) ${ }^{6}$ all had researched the KMV model from different perspectives. And conclusions of their research consistently indicated that the KMV model is effective and widely applicable.

At present, the applicability of the KMV model based on the data of Chinese companies remains controversial. Many domestic scholars have researched the applicability of the KMV model in Chinese context. However their conclusions are not consistent. Most Chinese scholars believe that the parameters of KMV model needs to be amended in order to suit for assessing credit risk of Chinese companies. Therefore, many 
researches about the amended KMV model emerging.

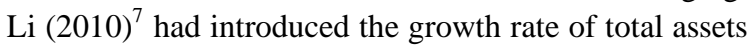
into the KMV model in order to describe the characteristics of business group; Peng (2011) ${ }^{8}$ had amended the KMV model under the market segmentation environment based on assumption of assets correlations. More amendments for KMV model focus on the amendments for the default point. That's because the determination of the default point has a certain degree of arbitrariness and subjectivity. A lot of experience has shown that the default point is equal to the sum of short term debt and half of the long term debt with the credit data of American companies. But many Chinese scholars doubt that whether the parameter of default point is suit for Chinese companies. For this reason, a number of literatures discussed the parameter of default point. Zhang (2010) ${ }^{9}$ Etc. exogenously given parameters based on qualitative analysis. All these method to determine parameter of default point have a certain degree of arbitrariness. Only Pan (2009) ${ }^{10}$ gave a quantitative methods to determine the parameter based on multiple regression. However both qualitative and quantitative researches are concluded inconsistent results. The research of Ma (2008) ${ }^{11}$ maybe can give some revelation. Different companies have different prediction accuracy with KMV model. The different parameter may adapt to companies in different industries.

Follow this idea, this paper first amends KMV model through a appropriate clustering method to determine the parameter of default point. Then the paper discusses the applicability of amended KMV model with different industries. There are two main innovations in this paper. First, this paper endogenously determines the parameter of default point. It improve the prediction accuracy of KMV model; second, this paper, to some extent, answers the reasons for the inconsistent results of the existing researches with the perspective of different industries.

\section{KMV Model}

The essence of KMV model is a kind of option pricing model which is rooted in the option pricing theory by Black-Scholes $^{12}$.The KMV model describes the bankruptcy as an endogenous event for a company. The affair of bankruptcy is determined by both the nominal value of liability of the company and the market value of the assets of the company at maturity date.

The KMV assumes that the value of the company follows a geometric Brownian motion which is the same as the assumption of Black-Scholes option pricing formula. Suppose the nominal value of liability of the company is $F$ and the market value of the assets of the company at maturity date is $V$. The company can't be in full settlement of its liability. The default occurs while the market value of the company's assets is less than the nominal value of the liability at maturity date, i.e. $V<F$. If the market value of the company's assets is higher than the nominal value of the liability at maturity date, i.e. $V>F$. The default of the company will not occur. The debtor's debt will be fully repaid. So the commercial banks loans to the company is equivalent to the company opened a put option, i.e. there is a put option that is held by the company. The exercise price of the option is the amount of loan debt. The underlying asset of the option is the market value of the company's assets. When the market value of the company's assets dropped to a certain level (called default threshold), the company will choose to implement the option. That is chose to default. Similarly, the loans can be also interpreted as a call option. The measure of credit risk with KMV is often divided into three basic steps. The first step is to estimate the market value of the company's assets $V$ and its fluctuation $\sigma_{V}$; The second step is to calculate the distance of default; And the last step is to convert the distance of default into probability of default.

According to the theory of option pricing by Black and Scholes, the analytical expression for the equity value is

$$
E_{t}=V_{t} N\left(d_{1}\right)-F e^{-r(T-t)} N\left(d_{2}\right)
$$

In which

$$
\begin{gathered}
d_{1}=\frac{\ln \left(V_{t} / F\right)+\left(r+\frac{\sigma_{V}^{2}}{2}\right)(T-t)}{\sigma_{V} \sqrt{T-t}} \\
d_{2}=d_{1}-\sigma_{V} \sqrt{T-t}
\end{gathered}
$$


$r$ is the risk-free rate, $E_{t}$ and $V_{t}$, respectively, the equity value and the value of total assets at the time $t$. $N(\cdot)$ is the distribution function of the standard normal distribution.

Further, according to the Ito Lemma, it can get the relationship between the fluctuation of equity value and the total assets, i.e. the relationship between $\sigma_{E}$ and $\sigma_{V}$.

$$
\sigma_{E}=\frac{V N\left(d_{1}\right)}{E} \sigma_{V}
$$

Simultaneous the formula (1) and the formula (2), it can have the key variable of the KMV model, i.e. $V$ and $\sigma_{V}$. Then the distance of default can be represented as follow.

$$
D D=\frac{V-D P}{V \sigma_{V}}
$$

If the probability distribution of assets is known, the expected default frequency (EDF) can be calculated. The KMV corporation gets the probability distribution of assets based on lot of historical credit data. In scientific research, it often uses standard normal distribution or lognormal distribution to describe the distribution of assets approximately. Assume the assets follow the standard normal distribution; the EDF can be interpreted as follow.

$$
\begin{aligned}
& E D F=\operatorname{Pr}(E(V)<D P) \\
& =N\left(\frac{D P-E(V)}{E(V) \sigma_{V}}\right) \\
& =N(-D D)
\end{aligned}
$$

\section{The Amendment of KMV Model}

The parameter of the default point in the KMV model is widely controversial because of its empirical and arbitrary. Most research defined the default point as the sum of short term debt (STD) and half of the long term debt (LTD). However, the parameter 0.5 is based on lots of American credit data. In china, many scholars doubt its adaptability of the parameter for Chinese company data of credit. But a great amount of research conclusions are not consistent. There may have two main reasons for this. First reason is that different companies may suit for different parameter of default point; Second reason is that many researches amended the parameter of default point exogenously based on qualitative analysis. They also have a certain degree of subjectivity and arbitrariness themselves.

Because of this, this paper first considered the differentiation of companies, dividing the companies into three basic industries, the traditional manufacturing, the commerce and trade industry, high-tech industry.

Then this paper divided the samples into two parts. One part is the training samples and the other part is the testing samples. In this way, the parameter of default point is determined endogenously.

Specifically, the paper applied the thought of clustering; assuming the parameter of default point is a undetermined parameter $\beta$. For a given industry and selected training samples, there are $n$ companies including $n_{1}$ ST companies and $n_{2}$ non-ST companies.

$$
n=n_{1}+n_{2}
$$

Denote the default point of the $n_{1}$ ST companies as $D P_{i 1}, D P_{i 2} \cdots \cdots P_{i n_{1}}$. Then the distance of default and the EDF of the $n_{1}$ ST companies are $D D_{i 1}, D D_{i 2}$ $\cdots \cdots D D_{i n_{1}}$ and $E D F_{i 1}, E D F_{i 2} \cdots \cdots E D F_{i n_{1}}$. Similarly it can denote the distance of default and the EDF of $n_{2}$ non-ST companies as $D D_{s 1}, D D_{s 2} \cdots \cdots$ $D D_{s n_{2}}$ and $E D F_{s 1}, E D F_{s 2} \cdots \cdots E D F_{s n_{2}}$.

For every company, the bivariate vector $\left(D D_{l p}, E D F_{l p}\right), l \in\{i, s\}$ describes its credit situation. As the distance of default and the EDF both depend on the parameter of default point $\beta$, the distance of default and the EDF can be also written as $D D_{l p}(\beta)$ and $E D F_{l p}(\beta)$.

For $n_{1}$ ST companies, the average distance of default and the average expected default frequency denote as

$$
\overline{D D}_{i}(\beta)=\frac{\sum_{k=1}^{n_{1}} D D_{i k}}{n_{1}}
$$

And

$$
\overline{E D F}_{i}(\beta)=\frac{\sum_{k=1}^{n_{1}} E D F_{i k}}{n_{1}}
$$

Similarly it can also define the average distance of default and the average expected default frequency of $n_{2}$ non-ST companies. 
Yang Yang et al.

$$
\overline{D D}_{s}(\beta)=\frac{\sum_{k=1}^{n_{2}} D D_{s k}}{n_{2}}
$$

And

$$
\overline{E D F}_{s}(\beta)=\frac{\sum_{k=1}^{n_{2}} E D F_{s k}}{n_{2}}
$$

Further, denote the

$$
\begin{aligned}
D F_{i} & =\left(\overline{D D}_{i}(\beta), \overline{E D F}_{i}(\beta)\right) \\
D F_{s} & =\left(\overline{D D}_{s}(\beta), \overline{\operatorname{EDF}}_{s}(\beta)\right)
\end{aligned}
$$

Learn from the thought of clustering; define the distance of ST companies and non-ST companies by Euclidean distance

$$
\begin{aligned}
& \Pi=\left|D F_{i}-D F_{s}\right| \\
& =\sqrt{\theta_{D D}^{2}+\theta_{E D F}^{2}}
\end{aligned}
$$

In which

$$
\begin{aligned}
& \theta_{D D}=\left(\overline{D D}_{i}(\beta)-\overline{D D}_{s}(\beta)\right) \\
& \theta_{E D F}=\left(\overline{E D F}_{i}(\beta)-\overline{E D F}_{s}(\beta)\right)
\end{aligned}
$$

Then determine the parameter of default point through the follow optimal problem

$$
\begin{aligned}
& \beta=\arg \max \Pi \\
& \text { s.t. } \quad \beta \in[0,10]
\end{aligned}
$$

Finally, the parameter $\beta$ is formulated endogenously by the optimal problem (13). This method to determine the parameter has two advantages. First, it increases the degree of freedom of the optimal problem. So that it can improve the accuracy and suitability of the KMV model; second, it correct the deviation of the assumption of standard normal distribution of assets based on sample data.

\section{The Empirical Test}

As the Chinese commercial banks are not open the list of default companies to the public, it's unable to obtain the actual data of default companies. This paper uses the approach that the most researches used, make the samples of ST companies in the Shanghai and Shenzhen A-share market as the samples of default companies.

This paper selects 180 companies as the samples from Shanghai and Shenzhen A-share market during 2006 to 2010, including 60 ST companies and 120 nonST companies. For each industry, it mentioned above, there are 20 ST company samples and 40 non-ST company samples.

In each industry, it selects training samples including 14 ST company samples and 30 non-ST company samples randomly. Then it uses the method which is introduced in the third part of this paper to formulate the parameter of default point. From this it can get parameters of default point in traditional manufacturing, commerce and trade industry and hightech industry respectively. These parameters are noted as $\beta_{1}, \beta_{2}$ and $\beta_{3}$.

From optimal problem (13), it can formulate the value of the parameters of default point which are listed in table 1below.

Table 1. Parameter of default point in different industries

\begin{tabular}{|c|l|l|}
\hline $\begin{array}{l}\text { Traditional } \\
\text { manufacturing }\end{array}$ & $\begin{array}{l}\text { Commerce \& } \\
\text { trade }\end{array}$ & $\begin{array}{l}\text { High-tech } \\
\text { industry }\end{array}$ \\
\hline$\beta_{1}=0.89$ & $\beta_{2}=0.68$ & $\beta_{1}=1.12$ \\
\hline
\end{tabular}

The parameter concluded in different industries shows that the applicability of KMV model is quite

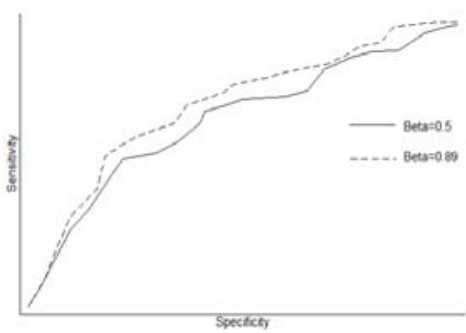

Fig.1. ROC in Traditional Manufacturing 
different for different industries. It illustrates the discussion of parameter of default point by different industries is effective and may explain the inconsistent of existing researches with different samples from a perspective.

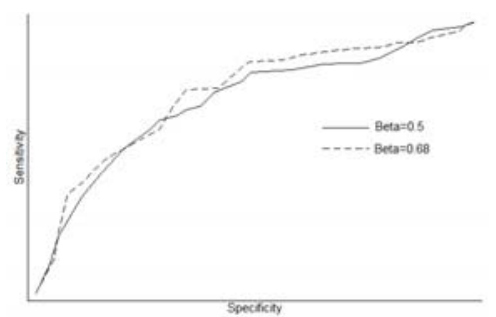

Figure2 ROC in Commerce \& Trade

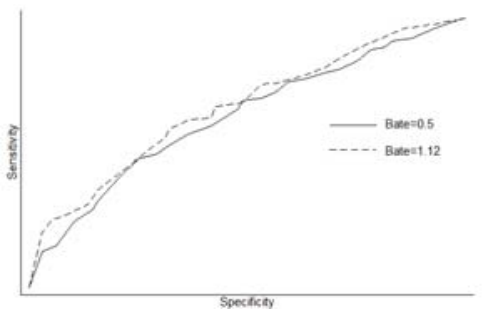

Fig.3. ROC in High-Tech industry

It can easily know from table1 that the parameter of default point in every industry of china is higher than the parameter of default point in traditional KMV model (the parameter of default point is equal to 0.5). This illustrates that the long term debt (LTD) is more important to the credit risk assessment for Chinese companies than American companies.

Further, it draws the ROC curve of full samples for each industry and the figure1, figure2 and figure3 express the ROC curve of full samples for traditional manufacturing, commerce \& trade industry and the high-tech industry respectively. From the figure 1 to figure 3, it can easily know that for each industry, the amended KMV models are more effective than the traditional KMV model. These figures also illustrate that the prediction accuracy of amended KMV model is higher than the traditional KMV model under the full samples' testing.

It has already indicated that the prediction accuracy of amended KMV model under the full samples. Then this paper will test the prediction of amended KMV model out of the training samples. As it said in above section, for each industry, this paper divided the samples into two parts, one part is the training samples including 14 ST company samples and 30 non-ST company samples; and the other part is the testing samples including 6 ST company samples and 10 nonST company samples.

First it uses the training samples to formulate the parameter of default point. Then it tests the prediction accuracy of the amended KMV model with the testing samples. In order to be consistent with the previous discussion, it select the same training samples as the paper did above, so the parameter of default point is concluded as table 1shows.

Compared with the traditional KMV model, the prediction accuracy in different industry is shown as follow, i.e. table 2 to table 4 .

Table 2. Prediction Accuracy of Traditional Manufacturing

\begin{tabular}{|l|c|l|}
\hline Accuracy & $\begin{array}{l}\text { Traditional KMV } \\
\text { model }\end{array}$ & $\begin{array}{l}\text { Amended KMV } \\
\text { model }\end{array}$ \\
\hline Type 1 Error & $16.7 \%$ & 0 \\
\hline Type 2 Error & $20 \%$ & $10 \%$ \\
\hline Total Accuracy & $81.25 \%$ & $93.75 \%$ \\
\hline
\end{tabular}

Table 2 shows the prediction accuracy of the industry of traditional manufacturing. In this industry, both type 1 error and type 2 error of amended KMV model is less than traditional KMV model. The total accuracy of amended KMV model is higher than traditional KMV model significantly.

Table 3. Prediction Accuracy of Commerce \& Trade Industry

\begin{tabular}{|l|c|c|}
\hline Mccuracy & $\begin{array}{l}\text { Traditional KMV } \\
\text { model }\end{array}$ & $\begin{array}{l}\text { Amended KMV } \\
\text { model }\end{array}$ \\
\hline Type 1 Error & $33.3 \%$ & $16.7 \%$ \\
\hline Type 2 Error & $30 \%$ & $10 \%$ \\
\hline Total Accuracy & $69.75 \%$ & $87.5 \%$ \\
\hline
\end{tabular}

Table 3 shows the prediction accuracy of the commerce and trade industry. In this industry, both type 
1 error and type 2 errors of amended KMV model is less than traditional KMV model. The total accuracy of amended KMV model is higher than traditional KMV model significantly.

Table 4. Prediction Accuracy of High-Tech Industry

\begin{tabular}{|l|c|c|}
\hline Accuracy & $\begin{array}{l}\text { Traditional KMV } \\
\text { model }\end{array}$ & $\begin{array}{l}\text { Amended KMV } \\
\text { model }\end{array}$ \\
\hline Type 1 Error & $50 \%$ & $16.7 \%$ \\
\hline Type 2 Error & $30 \%$ & 0 \\
\hline Total Accuracy & $62.5 \%$ & $93.75 \%$ \\
\hline
\end{tabular}

Table 4 shows the prediction accuracy of the Hightech industry. In this industry, both type 1 error and type 2 errors of amended KMV model is less than traditional KMV model. The total accuracy of amended KMV model is higher than traditional KMV model significantly.

Totally, from table 2 to table 4 it can easily conclude that the amended KMV model is better than the traditional KMV model consistently. The table 5 below shows the total accuracy of traditional KMV model and amended KMV model based on the data out of training samples.

Table 5. Prediction Accuracy of both KMV models

\begin{tabular}{|l|c|c|}
\hline Model & Traditional model & Amended model \\
\hline Accuracy & $70.83 \%$ & $91.67 \%$ \\
\hline
\end{tabular}

From the discussion above, it can get two conclusions. First is the parameter of default point has significant difference in different industries. Second is prediction accuracy of amended KMV model is higher than traditional KMV model consistently in all industries.

\section{Conclusions and Further Discussion}

The parameter of default point in traditional KMV model is experience concluded by the credit risk data of
American companies. Because of this, the applicability of the traditional KMV model with Chinese background is widely questioned by scholars. There are many researches that had amended the traditional KMV model in Chinese background. These researches have two defects. First, most of these researches amended the parameter of default point exogenously which leads to an inevitable problem of subjectivity and arbitrary. Second, these researches are concluded inconsistent with different samples. For these reasons, this paper first learns from the thought of clustering to determine the parameter of default point endogenously in different industries respectively. Then it compares the amended KMV model with the traditional KMV model with ROC curve in different industries based on full samples data. At last, this paper also tests the prediction accuracy out of the training samples. The research concluded two main results. One is the applicability of the KMV model may very difference in different industries; The other is the amended KMV model in this paper is better than the traditional KMV model consistently. These results of this paper may provide a think of application of KMV model in Chinese background on one hand and explain the inconsistent of existing researches in a certain extent.

Limited by the samples, the classification of industries in this paper is very rough. The reasonable of such classification is still need to be considered. Further discussion of classification criteria in a broader sense and deeper reasons of applicability of KMV model will help to understand KMV model deeper and applies it in Chinese background.

\section{References}

1. J. A. McQuown, A comment on market vs accountingbased measures of default risk, White Paper, Moody's KMV, (1993).

2. J. R. Bohn, Modeling, methodology, White Paper, Moody's KMV, (2003).

3. Stephen Kealhofer, Brian Dvorak, Modeling the default risk of unlisted firms, Research Reports of KMV, (2001).

4. Matthew Kurbat, Irina Korablev, Methodology for testing the level of the EDFTM credit measure, White Paper, Moody's KMV, (2002).

5. Peter Crodbie, Jeff Bohn Modeling default risk, Working Paper, KMV Corporation, (2003).

6. M. Stefan Denzler From default probabilities to credit spreads: credit risk models do explain market prices, 
Finance Research, 122(3): 439-462.

7. $\mathrm{Li} \mathrm{Li}$, Zongfang Zhou, Credit risk measure for business group based on modified KMV model, in $4^{\text {th }}$ annual meeting of risk analysis council of china association for disaster prevention(Changchun China, 2010): 837-842.

8. Daheng Peng, Congyu Zhang, Improvement of KMV model under market segmentation and its empirical analysis, Statistic \& Information Forum, 26, 5(2011):3338.

9. Nengfu Zhang, Jia Zhang, The application of amended KMV model in measuring credit risk of china listed companies, Forecasting, 29, 5(2010):48-52.

10. Jie Pan, Zongfang Zhou, Empirical study on revising default point in KMV model of public companies based on full circulation of stock, in $4^{\text {th }}$ annual meeting of enterprise operation of China (Huhehaote China, 2009):197-203.

11. Ruowei Ma. Testing KMV on the financial distress of listed companies in China, Application of Statics and Management, 5(2006):593-601.

12. F. Black and M. Scholes. The pricing of options and corporate liabilities, Journal of Political Economy, 5(1973):637-659. 